\title{
Fe-Ti-V ASSOCIADO AO GABRO DE LÍDICE, ESTADO DO RIO DE JANEIRO
}

\author{
Ronaldo Mello Pereira ${ }^{1}$, Marcelo dos Santos Salomão ${ }^{1}$, Reiner Neumann ${ }^{2}$, \\ Paulo Guimarães ${ }^{3}$, Enrico Pedroso ${ }^{1}$ \\ 1- Departamento de Geologia Aplicada da Faculdade de Geologia da Universidade do Estado do Rio de Janeiro (DGAp-FGEL/UERJ). \\ Rua São Francisco Xavier, 524 / 2017A, Rio de Janeiro - Rio de Janeiro. CEP: 20550-900. \\ E-mail: ronaldo.mellouerj@gmail.com / salomao.mss@gmail.com / e_pedroso@hotmail.com \\ 2- Centro de Tecnologia Mineral (CETEM/MCTI). Av. Pedro Calmon, 900 - Cidade Universitária, Rio de Janeiro - Rio de Janeiro. \\ CEP: 21941-908. E-mail: rneumann@cetem.gov.br \\ 3- Departamento de Recursos Minerais do Estado do Rio de Janeiro (DRM-RJ). Rua Marechal Deodoro, 351 - Centro, Niterói - Rio de Janeiro. \\ CEP: 24030-060. E-mail: pvguimaraes@drm.rj.gov.br
}

Recebido em 14 de maio de 2016; aceito em 6 de junho de 2016

\begin{abstract}
Resumo: O Gabro de Lídice corresponde a um corpo tabular, com cerca de 4,0 quilômetros de extensão e espessura entre 100 e 200 metros, constituído por hiperstênio, diopsídio, olivina, plagioclásio e minerais opacos (óxidos de Fe e Ti). Assinaturas petrográfica e geoquímica indicam caráter toleítico, entre os campos alcalino e subalcalino. O enriquecimento em $V$ é de 2 a 3 vezes maior do que o clarck esperado para tal tipo de rocha. O principal óxido é a titanomagnetita, com inclusões e exsoluções de ilmenita. O vanádio concentra-se principalmente na titanomagnetita, variando os teores entre $0,68 \%$ e 2,07\% de V2O5. Análises ICP-MS em pré-concentrado de titanomagnetita forneceram teores de 50,86\% de Fe2O3t, 13,56\% de TiO2 e 3.721 ppm de vanádio ( 0,66\% de V2O5). Quimicamente a ilmenita tem conteúdo em Fe2O3t (46,75\% a 48,80\%) e TiO2 (49,99\% a 51,36\%). Amostras enriquecidas em titanomagnetita exibem valores dos elementos terras raras e traço 30 vezes inferiores aos observados nas demais amostras. Ao longo de todo o corpo, a susceptibilidade magnética varia em escala centimétrica a decimétrica e está associada a concentrações anômalas de titanomagnetita na rocha, o que pode representar um bandamento magmático. Os dados apresentados sugerem uma origem associada a ambiente intraplaca.
\end{abstract}

Palavras Chave: Gabro, titanomagnetita, ilmenita, titânio, vanádio.

Abstract: Fe-Ti-V ASSOCIATED WITH LIDICE GABBRO, RIO DE JANEIRO STATE. The Gabbro of Lidice has about $4.0 \mathrm{~km}$ in length and thickness between 100 and 200 meters, consisting of pyroxene, olivine, plagioclase and opaque minerals (Fe and Ti oxides). Petrographic and geochemical signatures indicate toleitic character, between the alkaline and subalcalino fields. Vanadium enrichment is from 2 to 3 times higher than the expected clarck for such rock. The main oxide is titanomagnetite, with inclusions and exsolutions of ilmenite. Vanadium $(0,68 \%$ to $2,07 \% \mathrm{~V} 2 \mathrm{O} 5)$ is mainly concentrated in titanomagnetite. ICP-MS analyses in pre-concentrated of titanomagnetite provided levels of $50.86 \%$ of $\mathrm{Fe} 2 \mathrm{O} 3 \mathrm{t}, 13.56 \%$ of $\mathrm{TiO} 2$ and $3,721 \mathrm{ppm}$ of vanadium ( $0.66 \%$ de V2O5). Chemical analyses of ilmenite show content in Fe2O3t (from $46.75 \%$ to $48.80 \%$ ) and $\mathrm{TiO} 2$ (from $49.99 \%$ to $51.36 \%$ ). Samples enriched with titanomagnetite display values of trace and rare earth elements 30 times lower than those observed in other samples. Throughout the gabbro, the magnetic susceptibility varies from centimeter to decimeter scales and is associated with abnormal concentrations of titanomagnetite, which may represent magmatic banding. The data presented may suggest an origin associated with intraplate environment.

Keywords: Gabbro, titanomagnetite, ilmenite, titanium, vanadium.

\section{INTRODUÇÃO}

Gabros e noritos são registrados em várias regiões do Estado do Rio de Janeiro. No geral são corpos que passam despercebidos em virtude das suas pequenas dimensões, pois, constituem pequenos afloramentos métricos ou mesmo boudins centimétricos. Dentre eles, pode-se mencionar os corpos de rochas máficas e ultramáficas que aparecem principalmente na forma de blocos e afloramentos discretos, distribuídos entre Cambuci e São João do Paraíso (Mendes et al. 2011) e em Paracambi (Souza, 2010). Em outras localidades, entretanto, alguns desses corpos podem atingir uns poucos quilômetros de comprimento e dentre eles destacam-se os gabros de Marcos da Costa em Miguel Pereira (Junho et al., 1999), Amparo, na região de Nova Friburgo (Ludka \& Wiedmann, 1997), Conceição de Macabu (Trotta, 2004), Gleba Ribeiro / Santo Expedito em Papucaia / Guapimirim e o de Lídice, em Rio Claro (Pereira et al. 2015).

Os estudos desenvolvidos em alguns desses corpos rochosos (Marcos da Costa, Amparo e
Cambuci) foram somente do ponto de vista petrológico (Junho et al., 1999; Ludka \& Wiedemann, 1997; Mendes et al., 2011), sem que se tenha procurado estabelecer o seu potencial econômico para a presença de mineralizações em titânio e vanádio que porventura pudessem estar a eles associadas. Dessa forma, o presente trabalho, com o intuito de ampliar o conhecimento sobre essas rochas, propõe apresentar os dados geoquímicos, petrográficos e de química mineral, obtidos durante o estudo do gabro de Lídice e dar um viés econômico para esse corpo de modo a apontar para o seu potencial mineral em Ti e V.

\section{COMPARTIMENTAÇÃO GEOTECTÔNICA E GEOLÓGICA}

O Estado do Rio de Janeiro encontra-se integralmente contido no segmento central da Faixa Ribeira que compreende quatro terrenos tectonoestratigráficos empilhados em direção ao Cráton de São Francisco durante os eventos orogênicos ocorridos entre 605 e 580 Ma (Orogenia Brasiliana) e 530 e 490 Ma (Orogenia Búzios) e que são representados pelos terrenos Oriental e Ocidental, 
pela Klippe Paraíba do Sul e pelo Terreno Cabo Frio (Heilbron et al., 2000, 2004).

A região de Rio Claro está incluída no Terreno Ocidental sendo constituída por intercalações tectônicas entre o embasamento pré-1,7 Ga (Complexo Juiz de Fora) representado por rochas ortogranulíticas e as rochas metassedimentares neoproterozóicas que constituem a Megassequência Andrelândia (Heilbron et al., 2007). Os litotipos metassedimentares basicamente correspondem a gnaisses aluminosos constituídos por granada-biotita gnaisses bandados, às vezes com sillimanita, apresentando intercalações com rochas manganesíferas, biotita gnaisses bandados, rochas calcissilicáticas, sillimanita quartzitos, quartzitos puros e granada-plagioclásio gnaisse. No geral, o acamamento litológico é concordante com a foliação sendo esta marcante nas rochas metapelíticas e incipiente nas rochas metapsamíticas. As unidades litoestratigráficas presentes estão dispostas segundo a direção NE-SW, em concordância com a orientação geral da Faixa Ribeira e os mergulhos variam de 300 a 70o para NW e NNW.

Para Dutra (2013), em consonância com os trabalhos desenvolvidos anteriormente pela empresa Riofinex do Brasil e por Chaves (1987), a Megassequência Andrelândia, na área estudada, pode ser dividida em 10 unidades litoestratigráficas, sendo as mais representativas, para o presente trabalho, as unidades Lídice, São Roque e Valadão que representam as unidades encaixantes do corpo gabroide de Lídice (Figura 1).

\subsection{Gabros}

Grosso modo, os corpos gabroides encontrados na região sudeste do Brasil aparecem de forma isolada e, aparentemente, sua distribuição dá-se de acordo com vários trends paralelos entre si que, possivelmente marcam os limites / suturas entre diferentes terrenos acrescionários, alguns deles considerados pelos presentes autores como sendo Terrenos Khondalíticos. Esses terrenos, provavelmente, representam a extensão de um grande cinturão constituído por rochas khondalíticas que envolve as massas cratônicas do Gondwana (Figura 2). A esses alinhamentos de rochas básicas ainda se juntam uma série de pequenos corpos ultrabásicos, também isolados, como os de Liberdade e Ipanema em Minas Gerais.

No Estado do Rio de Janeiro essa distribuição dos corpos máficos dá-se segundo dois trends sendo que o mais oriental deles transcende para sul e norte as fronteiras estaduais, alinhando o gabro do Bairro Marisqueira, em Caraguatatuba, SP, com os gabros de Lídice (Município de Rio Claro) e de Marcos da Costa (Município de Miguel Pereira) ambos localizados em território fluminense e o gabro de Venda Nova, em Venda Nova do Imigrante, ES. Nesse mesmo alinhamento encontra-se o corpo ultrabásico de Areal, o mais conhecido do Estado do Rio de Janeiro (Figura 3).

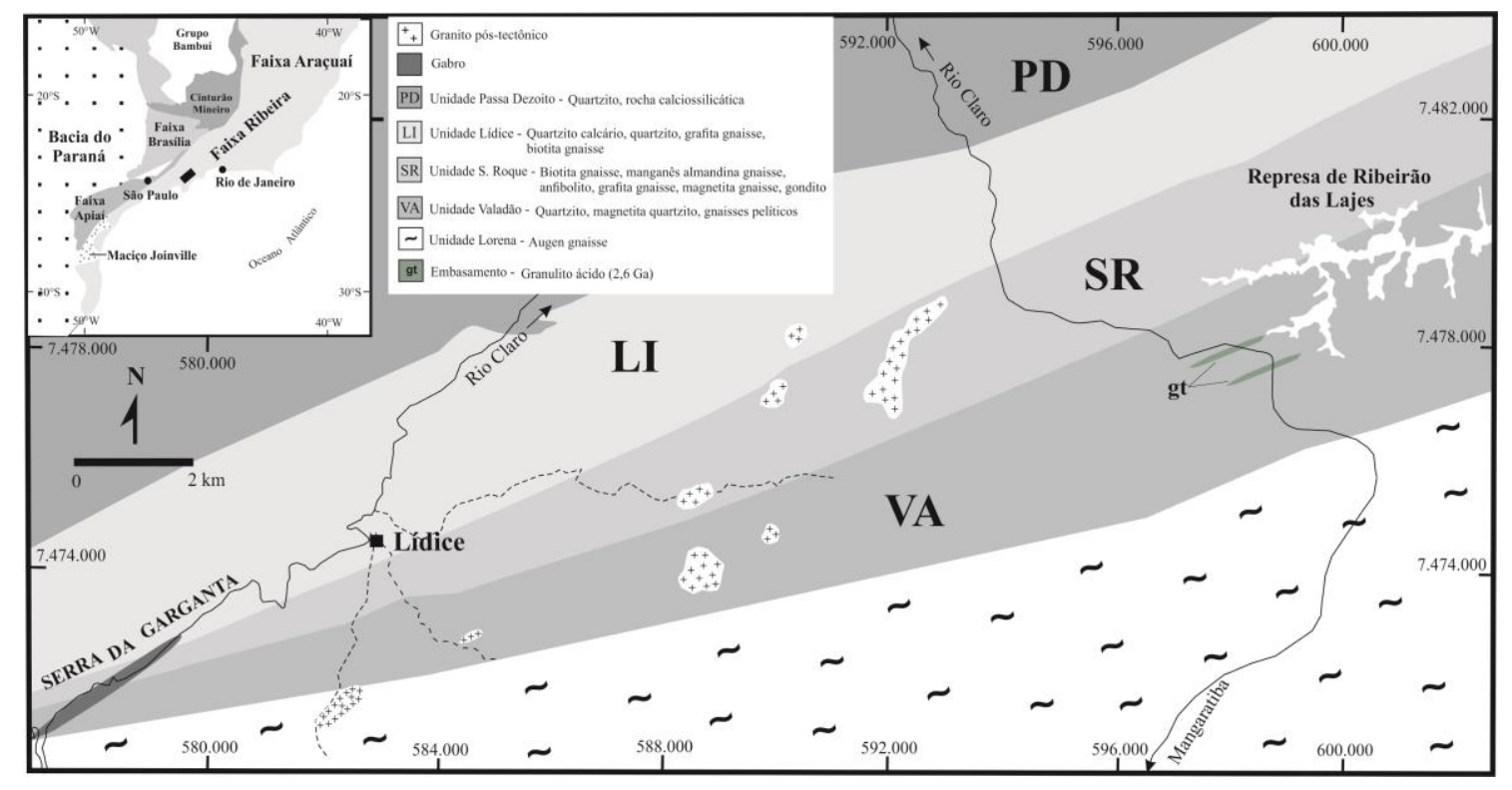

Figura 1. Mapa Geológico Esquemático da região de Rio Claro, RJ (modificado de Dutra, 2013). 


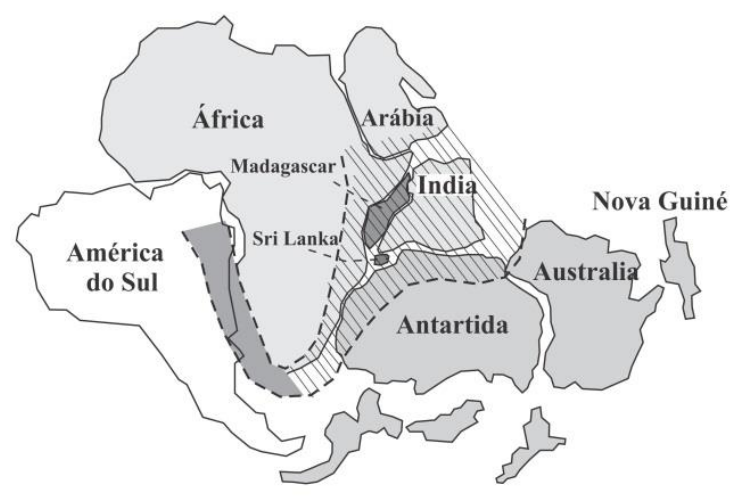

Figura 2. Terrenos khondalíticos e sua distribuição no Gondwana (adaptado de Wild et al. 1999). A área com hachuras corresponde aos terrenos khondalíticos com granulitos de baixa pressão (6-8

$K b)$. A área sombreada exibe a aprovável extensão desses

terrenos khondalíticos para o Brasil / América do Sul.

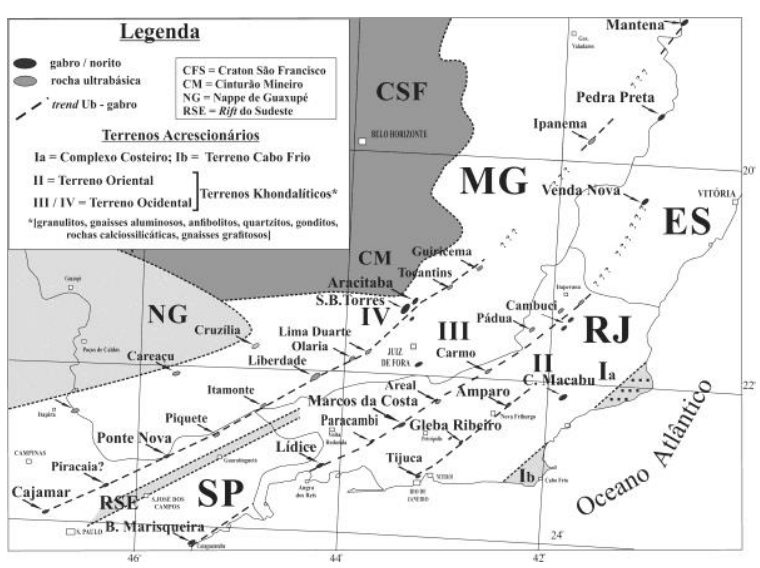

Figura 3. Distribuição de alguns corpos básicos (gabros e noritos) e ultrabásicos da região Sudeste do Brasil.

\subsection{Gabro de Lídice}

O gabro de Lídice corresponde a um corpo tabular com cerca de 4,0 quilômetros de extensão e espessura entre 100 e 200 metros, e está exposto desde a localidade de Lídice (Distrito de Rio Claro) até o desemboque do túnel rodoviário da RJ-155 que atravessa a Serra da Garganta, sentido BR-101 (rodovia Rio-Santos). A rocha tem cor escura, granulação variando de fina a média, e corresponde a um tipo maciço, de aspecto homogêneo. Em afloramento não se percebe a existência de bandamento de qualquer natureza. A rocha é fortemente magnética, o que pode ser facilmente constatado em campo por intermédio do uso do imã de mão e comprovado por intermédio de medidas de susceptibilidade magnética (SM).

O corpo encontra-se encaixado em um pacote de rochas metassedimentares (Figura 4), aí representadas por: quartzitos, quartzitos calcários, biotita gnaisses da Unidade Lídice, granada gnaisses da Unidade São Roque e magnetita quartzitos e magnetita gnaisses da Unidade Valadão (Dutra, 2013). Não há rochas ultrabásicas associadas a esse maciço.

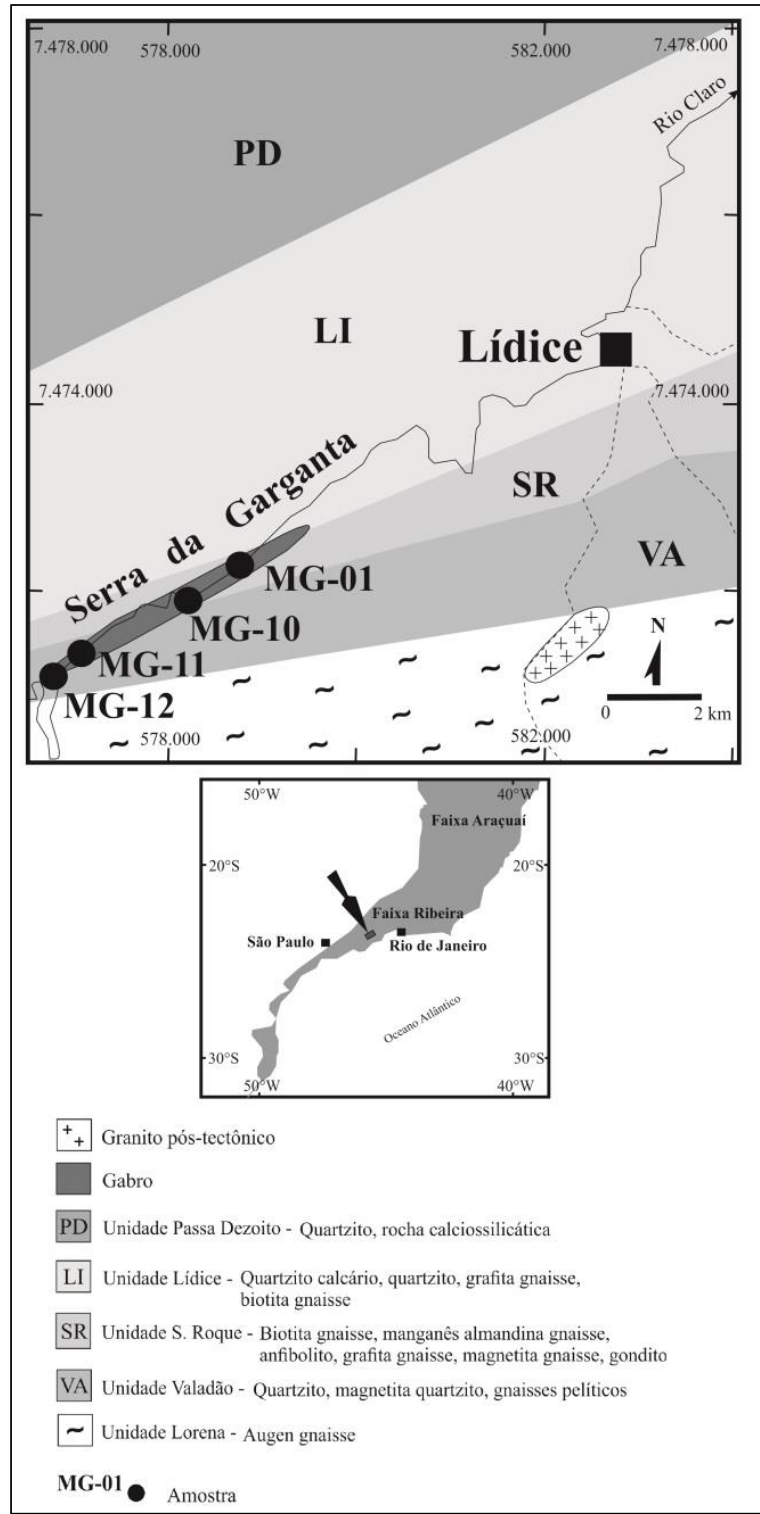

Figura 4. Detalhe do mapa Geológico Esquemático do corpo gabroide de Lídice, Rio Claro, RJ.

Em lâmina delgada, a rocha apresenta-se constituída por piroxênios representados por hiperstênio (80\%) e diopsídio (20\%), olivina, plagioclásio e minerais opacos, principalmente representados por óxidos de $\mathrm{Fe}$ e Ti. O principal óxido corresponde a um mineral ferromagnético que ocorre em grãos subhedrais e encontra-se disseminado na rocha. Seu conteúdo (em peso) nas amostras coletadas foi estimado em 7,6\% (MG-01A), 18,9\% (MG-10), 25,3\% (MG-11) e 8,3\% (MG-12). Após análises por MEV-EDS esse mineral foi considerado como sendo titanomagnetita. 


\section{MÉTODOS ANALÍTICOS}

Amostras do gabro de Lídice foram submetidas a diversos procedimentos analíticos, tais como análises para rocha total e multielementares para elementos menores, traços e ETR, análises multielementares em concentrados minerais, química mineral em amostras de magnetita e ilmenita e medidas de susceptibilidade magnética.

As análises de elementos menores, traços e ETR em rocha total e em pré-concentrado da fração ferromagnética foram realizadas no ActLabs, Canadá, e, para tal, as amostras foram submetidas aos procedimentos referentes ao Code 4 LITHO Major Elements Fusion ICP (WRA) / Trace Elements Fusion ICP /MS (WRA4B2).

A química mineral foi efetuada no laboratório de Microscopia Eletrônica do Centro de Tecnologia Mineral do Ministério da Ciência e Tecnologia (CETEM/MCT) situado no Rio de Janeiro. Para tal, seções polidas contendo amostras de titanomagnetita e ilmenita foram submetidas a análises no microscópio eletrônico de varredura FEI Quanta 400 com um sistema de microanálise química por dispersão de energia (EDS) Bruker Nano Quantax 800 acoplado e detector Bruker XFlash 5010, tecnologia SSD (silicon drift detector), com resolução espectral melhor que $129 \mathrm{eV}$ para $\mathrm{Mn} \mathrm{K \alpha}$. O MEV foi operado em alto vácuo, tensão de aceleração de elétrons de 25 kV, e spot size de 5 .

As composições químicas quantitativas dos minerais foram medidas por EDS, no sistema Bruker Quantax já descrito, no modo quantitativo sem padrões, com auto-calibração a partir da radiação de fundo (Bremstrahlung) da análise, correções ZAF por rotina $\Phi(\rho z)$, pelo softwareBruker Nano Esprit 1.9. A resolução da microanálise por EDS é da ordem de 1 micron de raio em superfície e em uma profundidade da ordem de 1,5 a 5 micrômetros, dependendo da densidade do material, no ponto analisado.

As medidas de susceptibilidades magnéticas foram efetuadas utilizando-se de susceptibilímetro marca EXPLORANIUM e modelo Kappameter KT-9 o qual permite medir materiais com SM entre $1 \times 10-5$ e 999x10-3 (SI-emu). As medidas de susceptibilidade foram tomadas em campo diretamente nos afloramentos rochosos e em laboratório em amostras de mão. Em campo, procurou-se efetuar as leituras em diferentes pontos dos afloramentos rochosos, de modo a identificar níveis ou camadas possuidoras de diferentes susceptibilidades magnéticas. As porções dos afloramentos com alteração intempérica visível foram evitadas. Em laboratório, as rochas tiveram quatro leituras de susceptibilidade, uma em cada face da amostra, sendo a susceptibilidade da mesma a média das medidas. Todas as medidas de susceptibilidades realizadas (amostras de mão e afloramentos) foram utilizadas para compor um valor de SM para o maciço gabroide estudado.

\section{RESULTADOS}

\subsection{Análise litogeoquímica}

Análises químicas de elementos maiores, menores e traços, incluindo os elementos terras raras, foram efetuadas em cinco amostras (Tabela 1). Embora em pequeno número para que se pudesse estabelecer uma análise mais aprofundada, a distribuição das amostras, coletadas de forma espaçada ao longo de todo o corpo gabroide, teve a perspectiva de que os resultados analíticos permitissem verificar as possíveis variações composicionais existentes, bem como propiciar o enquadramento geotectônico do Gabro de Lídice.

Os resultados obtidos indicam teores de $\mathrm{SiO} 2$ entre $47,06 \%$ e $50,66 \%$, Al2O3 entre 9,54\% e 14,62\%, TiO2 entre 4,21\% e 7,12\%, Fe2O3t entre $13,06 \%$ e $14,71 \%$, Na2O entre $2,08 \%$ e $2,88 \%, \mathrm{CaO}$ entre $7,97 \%$ e $9,63 \%, \mathrm{MnO}$ entre $0,181 \%$ e $0,203 \%$, K2O entre 1,01 e 1,61\% e P2O5 entre 0,25 e 0,55\%. Os valores de vanádio em rocha ficaram entre 441 ppm e 645 ppm.

Comparativamente ao padrão esperado para as rochas básicas, os conteúdos de $\mathrm{Cr}(50$ ppm a 100 ppm) e Ni (20 ppm a 70 ppm) são baixos, enquanto o conteúdo de vanádio (valores entre 440 ppm e 645 ppm) mostra um enriquecimento de 2 a 3 vezes maior do que o clarck esperado para tal tipo de rocha $(200 \mathrm{ppm})$. A totalidade do vanádio está concentrada na titanomagnetita.

Para Mendes et al. (2011), a maior parte dos diagramas utilizados na classificação geoquímica e tectônica das rochas básicas foram desenvolvidos para caracterizar tipos vulcânicos, mas, por analogia, eles também poderiam ser usados para os seus equivalentes plutônicos. Com tal, no diagrama $\mathrm{SiO} 2$ $x$ Na2O+K2O (Figura 5), verifica-se que as amostras do corpo efetivamente correspondem a gabros que se posicionam bem no limite entre os campos alcalino e subalcalino / toleítico, exceto a amostra MG-11 que cai no campo subalcalino / toleítico. Já no diagrama $\mathrm{Nb} / \mathrm{Y} \times \mathrm{Zr} / \mathrm{TiO} 2$ (Figura 6), as rochas estudadas são classificadas como alcalibasaltos. No gráfico ternário AFM (Figura 7) pode-se observar o predominante caráter toleítico das amostras. 


\begin{tabular}{|c|c|c|c|c|c|}
\hline Elemento & MG 01A & MG 10 & MG 11 & MG 12 & MG 14 \\
\hline $\mathrm{SiO}_{2}$ & 49.89 & 49.23 & 50.66 & 47.06 & 48.86 \\
\hline $\mathrm{TiO}_{2}$ & 4.21 & 4.51 & 4.83 & 7.12 & 4.51 \\
\hline $\mathrm{Al}_{2} \mathrm{O}_{3}$ & 13.83 & 13.59 & 9.54 & 14.31 & 14.62 \\
\hline $\mathrm{Fe}_{2} \mathrm{O}_{3} \mathrm{t}$ & 13.93 & 14.59 & 14.71 & 13.06 & 13.31 \\
\hline $\mathrm{MnO}$ & 0.181 & 0.186 & 0.203 & 0.163 & 0.161 \\
\hline MgO & 4.69 & 4.61 & 6.55 & 5.22 & 4.42 \\
\hline $\mathrm{CaO}$ & 8.41 & 8.42 & 9.29 & 9.63 & 7.97 \\
\hline $\mathrm{Na}_{2} \mathrm{O}$ & 2.87 & 2.77 & 2.08 & 2.81 & 2.88 \\
\hline $\mathrm{K}_{2} \mathrm{O}$ & 1.54 & 1.56 & 1.5 & 1.01 & 1.61 \\
\hline $\mathrm{P}_{2} \mathrm{O}_{5}$ & 0.46 & 0.55 & 0.5 & 0.25 & 0.43 \\
\hline LOI & 0.16 & 0.18 & 0.03 & 0.18 & 0.67 \\
\hline Total & 99.85 & 100.2 & 99.89 & 100.4 & 99.45 \\
\hline $\mathrm{Ag}$ & -- & -- & 0.5 & 0.7 & 0.8 \\
\hline $\mathrm{Ba}$ & 501 & 518 & 447 & 370 & 517 \\
\hline Cs & 1.4 & 1.4 & 1.1 & -- & 1.2 \\
\hline $\mathrm{Nb}$ & 21 & 25 & 20 & 19 & 19 \\
\hline Mo & 2 & 2 & 3 & -- & 3 \\
\hline $\mathrm{Pb}$ & 7 & 5 & 17 & 5 & 8 \\
\hline $\mathbf{R b}$ & 39 & 36 & 30 & 21 & 40 \\
\hline Sn & 2 & 2 & 2 & 1 & 2 \\
\hline $\mathrm{Sb}$ & 0.6 & -- & 0.6 & -- & 0.9 \\
\hline Sr & 692 & 691 & 412 & 772 & 671 \\
\hline $\mathrm{Zr}$ & 219 & 231 & 200 & 163 & 223 \\
\hline La & 31.6 & 35.8 & 35.1 & 19.5 & 32.3 \\
\hline $\mathrm{Ce}$ & 71.1 & 78.4 & 75.4 & 43.1 & 71.2 \\
\hline $\mathrm{Pr}$ & 9.22 & 10.1 & 9.79 & 5.48 & 8.77 \\
\hline $\mathrm{Nd}$ & 38.1 & 42.8 & 42 & 23.9 & 37.6 \\
\hline Sm & 8.4 & 9.2 & 8.9 & 5.5 & 8.3 \\
\hline Eu & 2.84 & 2.94 & 2.74 & 2.16 & 2.67 \\
\hline Gd & 7.6 & 8.1 & 8.2 & 4.9 & 7.1 \\
\hline $\mathbf{T b}$ & 1.1 & 1.2 & 1.2 & 0.7 & 1 \\
\hline Dy & 6.1 & 6.4 & 6.7 & 4.1 & 5.6 \\
\hline Ho & 1.2 & 1.2 & 1.2 & 0.8 & 1 \\
\hline $\mathrm{Er}$ & 3.1 & 3.1 & 3.3 & 2 & 2.7 \\
\hline $\mathrm{Tm}$ & 0.4 & 0.45 & 0.4 & 0.27 & 0.37 \\
\hline $\mathrm{Yb}$ & 2.5 & 2.7 & 2.7 & 1.7 & 2.2 \\
\hline Lu & 0.4 & 0.39 & 0.4 & 0.25 & 0.34 \\
\hline$Y$ & 24 & 27 & 25 & 18 & 25 \\
\hline Hf & 5.4 & 6.1 & 5.8 & 4.1 & 5.6 \\
\hline $\mathrm{Ta}$ & 1.6 & 1.7 & 1.5 & 2.2 & 2 \\
\hline Th & 3.9 & 4 & 4.1 & 2.3 & 5.4 \\
\hline $\mathbf{U}$ & 0.9 & 0.9 & 1 & 0.5 & 1.3 \\
\hline $\mathbf{w}$ & 59 & 4 & 63 & 45 & 3 \\
\hline
\end{tabular}

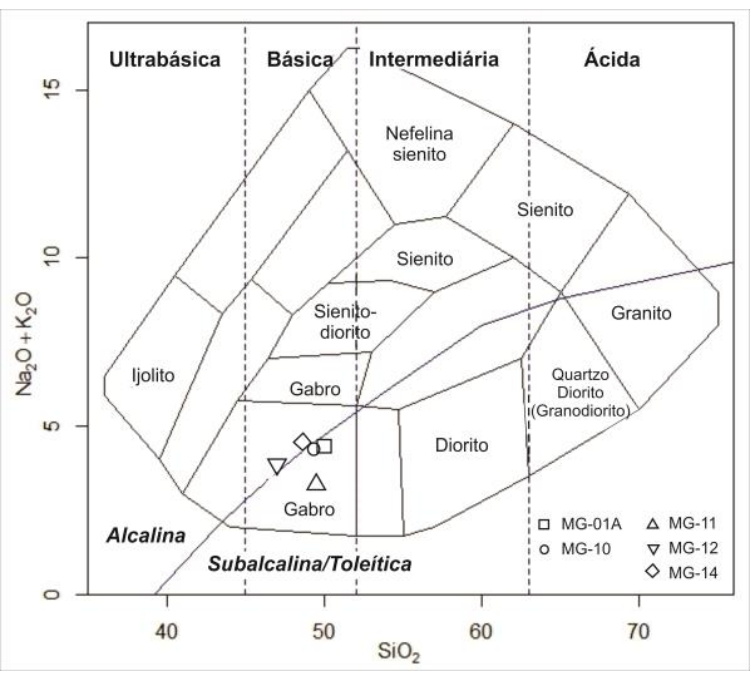

Figura 5. Diagrama $\mathrm{SiO} 2$ x Na2O+K2O (Cox et al., 1979) para classificação das rochas estudadas.

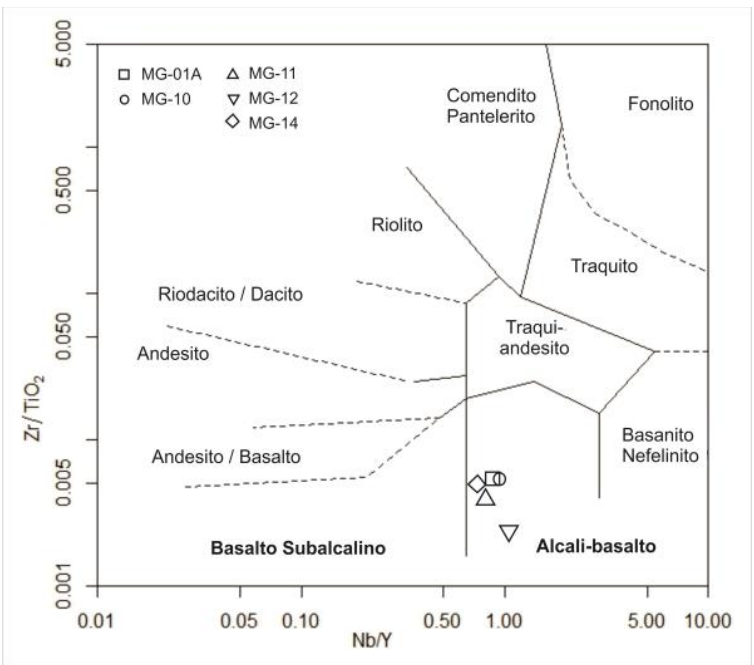

Figura 6. Diagrama $\mathrm{Nb} / \mathrm{Y} \times \mathrm{Zr} / \mathrm{TiO} 2$ (Winchester \& Floyd, 1977) para classificação das rochas estudadas.

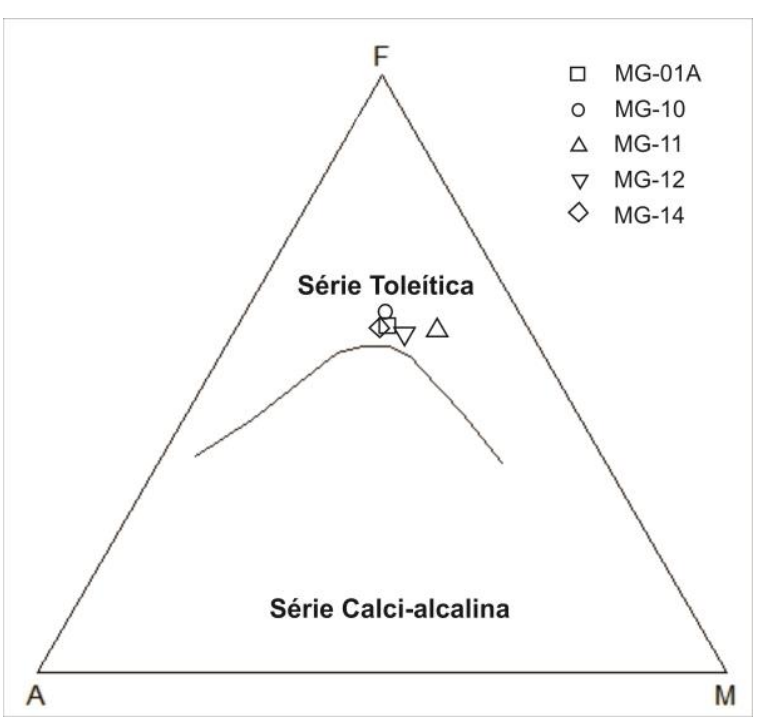

Figura 7. Diagrama AFM (Irvine \& Baragar, 1971) para as rochas estudadas. 
Em relação ao comportamento dos ETR (Figura 8), observa-se que todas as amostras exibem valores superiores ao normalizado para o condrito, com um trend demonstrando um empobrecimento dos ETRs pesados em comparação com os leves. Diferenças significativas são observadas entre as partes mais enriquecidas em titanomagnetita (amostras MG-01A e MG-12) das partes menos mineralizadas, com valores aproximadamente 30 vezes inferiores nas ocorrências enriquecidas.

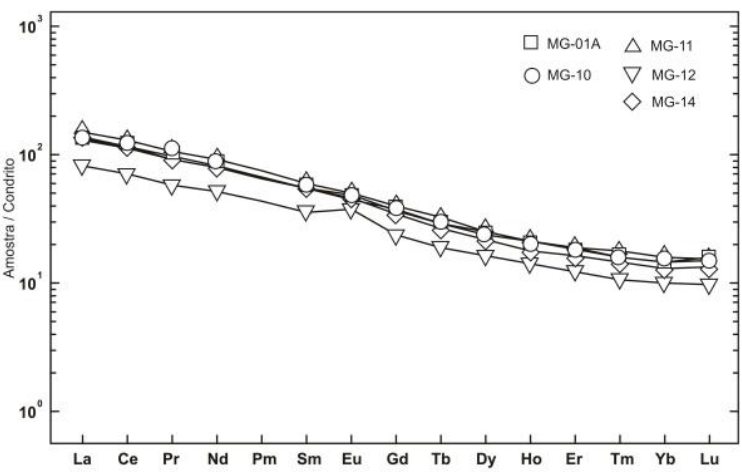

Figura 8. Padrões de ETR, normalizados para o condrito (McDonough \& Sun, 1995; Sun \& McDonough, 1989) para as rochas estudadas.

O diagrama multielementar de elementos-traço, normalizados segundo valores para manto primordial (Figura 9), exibe vértices negativos para $\mathrm{Th}, \mathrm{Nb}$ e Sm. No diagrama destaca-se a anomalia positiva para o elemento $\mathrm{Ti}$, com valores entre $20 \mathrm{e}$ 70 vezes acima do valor de referência.

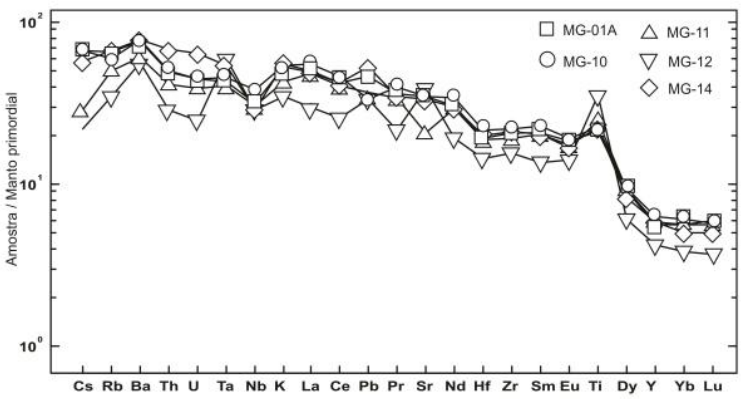

Figura 9. Padrões de elementos-traço, normalizados para o manto primordial (McDonough \& Sun, 1995; Sun \& McDonough, 1989) para as rochas estudadas.

\subsection{Análise química mineral}

Análises em MEV-EDS indicam que o mineral ferromagnético presente no Gabro de Lídice corresponde à titanomagnetita (Figura 10), o termo de alta temperatura da solução sólida magnetitaulvo espinélio (Buddington \& Lindsley, 1964). Esse mineral apresenta-se com inclusões e exsoluções de ilmenita (Figura 11).
Vinte e um grãos de titanomagnetita foram analisados e os resultados apresentados na Tabela 2. Os valores de Fe2O3t variaram entre $83,62 \%$ e 76,44\%; de $\mathrm{TiO} 2$ entre $19,46 \%$ e $12,25 \%$ e V2O5 entre $2,07 \%$ e $0,68 \%$. Os teores de cromo e níquel são baixos, negligenciáveis.

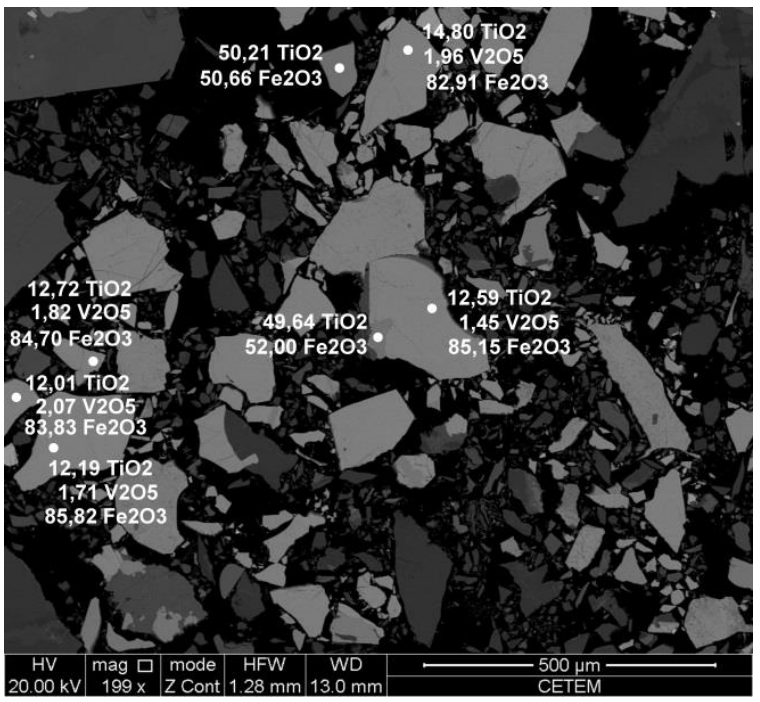

Figura 10. Imagem Back scattered electron mostrando os grãos de Ti-magnetita vanadinífera da amostra MG-14.

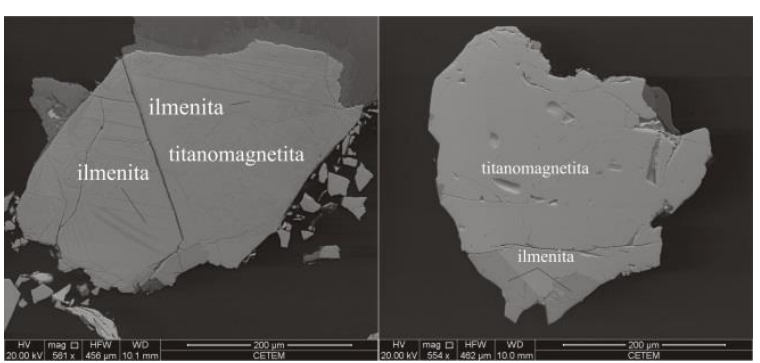

Figura 11. Imagem Back scattered electron de titanomagnetita (amostra MG-01) do gabro de Lídice com exsoluções de ilmenita.

Quimicamente a ilmenita, presente como exsoluções e inclusões na titanomagnetita tem conteúdo em Fe2O3t entre 46, $75 \%$ e 48,80 \% e TiO2 entre 49,99 \% e 51,36 \%. O vanádio está praticamente ausente, salvo o que foi detectado na amostra MG-10 (Tabela 3).

Amostras do ponto MG-01A foram britadas e pulverizadas e depois tiveram a titanomagnetita removida com auxílio de um imã de mão. 0 percentual (em peso) da titanomagnetita presente foi calculado e uma alíquota desse material foi retirada para análise química por ICP-MS para determinar os teores de Fe2O3, TiO2 e V2O5 e demais elementos associados. Os valores obtidos foram de: $50,86 \%$ de Fe2O3t, 13,56\% de TiO2 e $3.721 \mathrm{ppm}$ de vanádio (equivalente a 0,66\% V2O5). Os demais elementos presentes foram: Co (121 ppm), Cr (189 ppm), Cu (62 ppm), Ni (140 ppm), Sc (23 ppm), Zn (473 ppm). 
Tabela 2. Composição química em MEV-EDS da titanomagnetita.

\begin{tabular}{|c|c|c|c|c|c|c|c|c|c|c|c|c|c|c|c|c|c|c|c|c|c|}
\hline \multirow{2}{*}{$\frac{\text { Elemento }}{\mathrm{Fe}_{2} \mathrm{O}_{3} \mathrm{t}}$} & \multicolumn{4}{|c|}{ MG-01A } & \multicolumn{5}{|c|}{ MG-10 } & \multicolumn{5}{|c|}{ MG-11 } & \multicolumn{2}{|c|}{ MG-12 } & \multicolumn{5}{|c|}{ MG-14 } \\
\hline & 79.25 & 77.85 & 78.94 & 79.95 & 82.36 & 82.22 & 81.06 & 77.32 & 77.18 & 77.81 & 78.69 & 74.25 & 83.62 & 76.92 & 76.44 & 83.46 & 84.7 & 83.83 & 85.82 & 85.15 & 82.91 \\
\hline $\mathrm{TiO}_{2}$ & 15.83 & 16.64 & 16.76 & 16.05 & 12.25 & 12.87 & 13.2 & 18.09 & 14.5 & 17.49 & 16.34 & 18.35 & 11.79 & 19.09 & 19.46 & 12.86 & 12.72 & 12.01 & 12.19 & 12.59 & 14.8 \\
\hline $\mathrm{V}_{2} \mathrm{O}_{5}$ & 1.4 & 1.55 & 1.56 & 1.38 & 1.55 & 1.38 & 1.59 & 1.21 & 1.52 & 1.14 & 1.47 & 1.08 & 1.01 & 1.3 & 1.25 & 0.68 & 1.82 & 2.07 & 1.71 & 1.45 & 1.96 \\
\hline $\mathrm{Al}_{2} \mathrm{O}_{3}$ & 2.3 & 2.15 & 2.05 & 2.04 & 1.81 & 1.99 & 2.32 & 1.94 & 2.46 & 2.12 & 1.33 & 2.2 & 2.11 & 1.61 & 2.12 & 1.76 & 2.34 & 2.7 & 1.64 & 1.95 & 2.06 \\
\hline $\mathrm{SiO}_{2}$ & 0.2 & 0.12 & - & - & - & 0.3 & 0.52 & 0.48 & 2.56 & 0.58 & 0.93 & 1.79 & 0.39 & 0.27 & 0.33 & 0.46 & - & - & - & 0.21 & - \\
\hline $\mathrm{MgO}$ & 0.45 & 0.21 & 0.52 & 0.41 & 0.1 & 0.2 & 0.12 & 0.29 & 0.21 & 0.21 & - & 0.16 & 0.1 & 0.1 & 0.08 & - & - & 0.05 & 0.2 & 0.16 & - \\
\hline $\mathrm{MnO}$ & 0.45 & 0.53 & 0.14 & 0.14 & 0.9 & 1 & 1.19 & 0.66 & 0.94 & 0.65 & 1.09 & 1.77 & 0.95 & 0.72 & 0.26 & 0.78 & 0.81 & 0.57 & 0.54 & 0.71 & 0.85 \\
\hline
\end{tabular}

Tabela 3. Composição química da ilmenita presente como exsoluções e inclusões na titanomagnetita.

\begin{tabular}{cccccc}
\cline { 2 - 6 } & \multicolumn{5}{c}{ Amostra } \\
\hline Elemento & MG-01A & MG-10 & MG-11 & MG-12 & MG-14 \\
\hline $\mathrm{Fe}_{2} \mathrm{O}_{3} \mathrm{t}$ & 48.80 & 48.23 & 47.47 & 46.75 & 50.65 \\
\hline $\mathrm{TiO}_{2}$ & 49.99 & 50.10 & 50.95 & 51.36 & 50.21 \\
\hline $\mathrm{V}_{\mathbf{2}} \mathrm{O}_{5}$ & --- & 0.15 & --- & --- & --- \\
\hline $\mathrm{Al}_{2} \mathrm{O}_{3}$ & 0.10 & 0.08 & 0.02 & 0.15 & 0.06 \\
\hline $\mathrm{SiO}_{2}$ & 0.20 & 0.10 & 0.32 & 0.29 & 0.13 \\
\hline $\mathbf{M g O}$ & 0.79 & 0.72 & 0.45 & 0.68 & 1.81 \\
\hline $\mathbf{M n O}$ & 0.12 & 0.61 & 0.76 & 0.70 & 0.63 \\
\hline
\end{tabular}

\section{RESULTADOS}

O Gabro de Lídice possui assinaturas petrográfica e geoquímica próprias de toleítos, posicionando-se no limite entre os campos alcalino e subalcalino. A exceção é a amostra MG-11 com característica subalcalina / toleítica. No geral, seu aspecto é granular e homogêneo sem que se pudesse observar, em escala de afloramento, a presença de texturas primárias como acumulação de cristais e orientação por fluxo. A mineralogia original das rochas mostra associação mineral anidra e está bem representada pela coexistência de orto e clinopiroxênios e plagioclásio.

Quimicamente, o conjunto de rochas estudadas exibe concentrações elevadas de Ti e V, o segundo com valores anômalos. Os dados geoquímicos do gabro de Lídice demonstram algumas variações composicionais entre as amostras coletadas no maciço. Essas diferenças manifestam-se sob a forma de um enriquecimento em TiO2 (MG-12), um enriquecimento um pouco mais acentuado com relação ao $\mathrm{MgO}$ e $\mathrm{CaO}$ (MG-11 e MG-12) e um empobrecimento em relação ao Al2O3 (MG-11) e P2O5 (MG-12).

Os padrões de ETR apresentam anomalias superiores ao normalizado para o condrito, com padrão de empobrecimento dos elementos pesados em relação aos leves. No diagrama multielementar de McDonough \& Sun (1995) e Sun \& McDonough (1989) para os elementos LILE são observados padrões compatíveis com ambiente de arco continental e envolvimento de porções crustal e mantélica.
Comparativamente aos demais corpos gabroides dispostos ao longo do trend oriental, (Tabela 4) verificam-se algumas variações composicionais entre eles. O gabro de Lídice, seguido do gabro Marcos da Costa, são os que apresentam os maiores valores de $\mathrm{TiO} 2, \mathrm{~K} 2 \mathrm{O}$, Ba e Zr, e os menores conteúdos de MgO, $\mathrm{CaO}, \mathrm{Cr}$ e $\mathrm{Ni}$ em relação aos corpos de Cambuci e de Venda Nova.

Em relação a gabros mineralizados em Fe-Ti-V e que constituem minas na Finlândia, Egito e China, verifica-se que o gabro de Lídice apresenta valores de titânio e vanádio compatíveis, se não algo superiores, aos determinados em alguns desses corpos (Tabela 5). Em média, o gabro de Lídice revela teores de $\mathrm{TiO} 2$ mais elevados, $\mathrm{SiO} 2, \mathrm{Al} 2 \mathrm{O} 3$, Fe2O3t, $\mathrm{Na} 2 \mathrm{O}, \mathrm{CaO}, \mathrm{MnO}, \mathrm{MgO}$ equivalentes e $\mathrm{K} 2 \mathrm{O}$ menos acentuado, comparativamente à composição química de basaltos de ilhas oceânicas e basaltos intraplaca.

A amostra mais enriquecida em titanomagnetita (MG-12) apresenta valores dos elementos terras raras e traços aproximadamente 30 vezes inferiores aos observados nas demais amostras. A exceção é o elemento $\mathrm{Ti}$, que na amostra MG-12 exibe valor 10 vezes superior às demais amostras.

Considerando-se os diagramas discriminantes de ambiente tectônico de rochas basálticas usando elementos de baixa mobilidade ( $\mathrm{Zr} \times \mathrm{Ti}$ e $\mathrm{Zr}-\mathrm{Zr} / \mathrm{Y}$ ) verifica-se que as rochas estudadas caem essencialmente no campo dos basaltos intraplaca (Figuras 12 e 13). Da mesma forma, há uma concordância com relação aos gabros Marcos da Costa e Venda Nova cujas análises em sua maioria também se posicionam no campo dos basaltos intraplaca. Para Junho et al. (1999), o corpo de Marcos da Costa, que está disposto no mesmo trend que contém o gabro de Lídice, corresponde a uma intrusão básica que ocorreu na crosta inferior durante o evento metamórfico de alto grau que afetou as rochas da região, exibindo uma fase híbrida representada por quartzogabro. Já os pequenos corpos gabroides da área de Cambuci diferenciam-se dos demais, sendo associados ao magmatismo gerado em ambiente de cadeias mesooceânicas. 
Tabela 4. Comparação entre os valores composicionais do gabro de Lídice (GL), Marcos da Costa, Cambuci* e Venda Nova* (*dados de Mendes et al. 2002; 2011).

\begin{tabular}{|c|c|c|c|c|c|c|c|c|c|c|c|c|c|c|c|c|c|c|c|c|c|c|c|}
\hline \multicolumn{6}{|c|}{ LÍDICE } & \multicolumn{5}{|c|}{ MARCOS DA COSTA } & \multicolumn{4}{|c|}{ CAMBUCI } & \multicolumn{9}{|c|}{ VENDA NOVA } \\
\hline Elem. & $\begin{array}{c}\text { MG } \\
01\end{array}$ & $\begin{array}{c}\text { MG } \\
10\end{array}$ & $\begin{array}{c}\text { MG } \\
11\end{array}$ & $\begin{array}{c}\text { MG } \\
12\end{array}$ & $\begin{array}{c}\text { MG } \\
14\end{array}$ & $\begin{array}{l}\text { MC } \\
01\end{array}$ & $\begin{array}{c}\text { MC } \\
02\end{array}$ & $\begin{array}{l}\text { MC } \\
06\end{array}$ & $\begin{array}{l}\text { MC } \\
07\end{array}$ & $\begin{array}{c}\text { MC- } \\
8 \mathrm{~A}\end{array}$ & \begin{tabular}{|c} 
ESM \\
22
\end{tabular} & $\begin{array}{c}\text { AM } \\
09\end{array}$ & $\begin{array}{c}\text { AMP } \\
\text { MV }\end{array}$ & $\begin{array}{c}\text { ESM } \\
18\end{array}$ & $\begin{array}{c}\text { VN } \\
3\end{array}$ & $\begin{array}{c}\text { VN } \\
5\end{array}$ & $\begin{array}{c}\text { VN } \\
6\end{array}$ & $\begin{array}{c}\text { VN } \\
7\end{array}$ & $\begin{array}{c}\text { VN } \\
8\end{array}$ & $\begin{array}{c}\text { VN } \\
9\end{array}$ & $\begin{array}{l}\text { VN } \\
10\end{array}$ & $\begin{array}{l}\text { VN } \\
11\end{array}$ & $\begin{array}{l}\text { VN } \\
14\end{array}$ \\
\hline $\mathrm{SiO}_{2}$ & 9.89 & 49.23 & 50.66 & 47.06 & 48.86 & .28 & 46.89 & 53.73 & 46.87 & 45.44 & 47.63 & 47.59 & 47.41 & 47.24 & 43.88 & 42.17 & 46.45 & 43.84 & 45.27 & 43.38 & 43.29 & 48.88 & 46.57 \\
\hline $\mathrm{TiO}_{2}$ & 4.21 & 4.51 & 4.83 & 7.124 & 4.515 & 1.736 & 4.44 & 363 & 3.806 & 3.957 & 1.09 & 1.2 & 1.29 & 1.06 & 2.15 & 2.46 & 1.69 & 1.53 & 1.47 & 2.31 & 1.65 & 1.19 & 0.99 \\
\hline $\mathrm{Al}_{2} \mathrm{O}_{3}$ & 13.83 & 13.59 & 9.54 & 14.31 & 14.62 & 14.43 & 14.33 & 13.63 & 14.78 & 15.58 & 15.02 & 9.75 & 12.9 & 14.97 & $\mid 18.19$ & 18.69 & $\mid 19.16$ & $\mid 18.29$ & 18.21 & 18.25 & 18.81 & 17.69 & 18.44 \\
\hline $\mathrm{Fe}_{2} \mathrm{O}_{3} \mathrm{t}$ & 13.93 & 14.59 & 14.71 & 13.06 & 13.31 & 12.44 & 16.43 & 13.63 & 16.45 & 15.54 & 12.31 & 11.86 & 15.80 & 12.48 & 14.53 & 15.68 & 13.37 & 13.66 & 13.04 & 14.91 & 13.97 & 12.97 & 10.91 \\
\hline $\mathrm{MnO}$ & 0.18 & 0.19 & 0.20 & 0.16 & 0.16 & 0.20 & 0.24 & 0.23 & 0.22 & 0.20 & 0.21 & 0.17 & 0.25 & 0.20 & 0.21 & 0.2 & 0.21 & 0.21 & .19 & 1 & 0.19 & 0.22 & 18 \\
\hline $\mathrm{MgO}$ & 4.69 & 4.61 & 6.55 & 5.22 & 4.42 & 5.72 & 5.4 & 2.89 & 4.58 & 5.23 & 11.61 & 14.82 & 8.36 & 11.36 & 5.67 & 3.42 & 4.86 & 6.30 & 6.46 & 5.75 & 6.49 & 5.85 & 4.79 \\
\hline $\mathrm{CaO}$ & 8.41 & 8.42 & 9.29 & 9.63 & 7.97 & 9.03 & 9.35 & 6.56 & 9.04 & 8.75 & 9.38 & 12.20 & 11.68 & 9.54 & $\mid 11.98$ & 12.61 & 10.80 & \begin{tabular}{|l|}
13.36 \\
\end{tabular} & 12.72 & 12.75 & 13.38 & 10.80 & 13.28 \\
\hline $\mathrm{Na}_{2} \mathrm{O}$ & 2.87 & 2.77 & 2.08 & 2.81 & 2.88 & 2.94 & 2.91 & 3.22 & 2.95 & 2. & 2.70 & 0.99 & 2.23 & 2.65 & 1.67 & .34 & 2.25 & 0.67 & 1.79 & 0.74 & 0.72 & 1.56 & 0.66 \\
\hline $\mathrm{K}_{2} \mathrm{O}$ & 1.54 & 1.56 & 1.50 & 1.01 & 1.61 & 0.79 & 0.61 & 2.01 & 0.67 & 1.23 & 0.07 & 0.99 & 0.23 & 0.06 & 0.27 & 0.28 & 0.28 & 0.11 & 0.18 & 0.14 & 0.11 & 0.43 & 0.13 \\
\hline $\mathrm{P}_{2} \mathrm{O}_{5}$ & 0.46 & 0.55 & 0.50 & 0.25 & 0.43 & 0.42 & 0.5 & 1.19 & 0.5 & 0.64 & 0.07 & 0.15 & 0.08 & 0.06 & 0.76 & 0.81 & 0.48 & 0.39 & 0.30 & 0.64 & 0.35 & 0.32 & 0.16 \\
\hline LOI & 0.16 & 0.18 & - & \begin{tabular}{|l|}
-0.18 \\
\end{tabular} & 0.67 & 0.71 & $-0.25 \mid$ & 0.44 & $\mid-0.33$ & 1.16 & 0.40 & 0.17 & 0.08 & 0.17 & 0.28 & 0.17 & 0.39 & \begin{tabular}{|l|}
0.41 \\
\end{tabular} & 0.14 & 0.29 & 0.35 & \begin{tabular}{|l|}
0.26 \\
\end{tabular} & 0.5 \\
\hline total & 99.85 & 100.2 & 99.89 & $\mid 100.4$ & 99.45 & 98.69 & 100.8 & 100 & 99.54 & 100.5 & 100.5 & 99.79 & 100.2 & 99.63 & 99.59 & 99.84 & 99.94 & 99.27 & 99.17 & 99.37 & 99.31 & 99.57 & 99.62 \\
\hline $\mathrm{Ba}$ & 501 & 518 & 401 & 370 & 517 & 222 & 309 & 509 & 333 & 547 & - & 419 & 1 & - & 130 & 8 & 159 & 35 & 8 & 29 & 53 & 284 & 62 \\
\hline $\mathrm{Rb}$ & 39 & 36 & 30 & 21 & 40 & 40 & 13 & 95 & 13 & 36 & 21 & 37 & 19 & 20 & - & - & - & - & - & - & - & - & - \\
\hline $\mathrm{Sr}$ & 692 & 691 & 412 & 772 & 671 & 330 & 335 & 325 & 369 & 367 & 239 & 261 & 152 & 242 & 481 & 479 & 554 & 439 & 418 & 435 & 454 & 453 & 391 \\
\hline $\mathrm{Zr}$ & 219 & 231 & 200 & 163 & 223 & 86 & 96 & 306 & 91 & 191 & 71 & 95 & 55 & 70 & 154 & 106 & 149 & 39 & 97 & 76 & 46 & 139 & 38 \\
\hline Y & 24 & 27 & 25 & 18 & 25 & 21 & 22 & 45 & 24 & 26 & 17 & $2 c$ & 20 & 17 & 3 & 41 & 31 & 12 & 26 & 16 & 13 & 22 & 11 \\
\hline v & 441 & 488 & 594 & 645 & 447 & 271 & 505 & 157 & 551 & 450 & 14 & 169 & 178 & 14 & 297 & 323 & 278 & 377 & 381 & 452 & 447 & 240 & 292 \\
\hline $\mathrm{Cr}$ & 70 & 50 & 100 & 70 & 80 & 30 & 50 & 20 & 20 & 30 & 199 & 1024 & 202 & 218 & 30 & 24 & 11 & 22 & 14 & 29 & 7 & 33 & 24 \\
\hline $\mathrm{Ni}$ & 20 & 70 & 2 & - & - & - & - & - & - & - & 334 & 5 & 70 & 328 & 20 & 20 & 18 & 29 & 13 & 18 & 11 & 23 & 22 \\
\hline $\mathrm{Nb}$ & 21 & 25 & 20 & 19 & 19 & 11 & 10 & 12 & 12 & 10 & f & 10 & 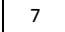 & 0 & 13.7 & 15 & $\mid$\begin{tabular}{|l|}
12.2 \\
\end{tabular} & 6 & 8.2 & 8.6 & 5.4 & 9.4 & 6 \\
\hline La & 31.6 & 35.8 & 5.1 & 19.5 & 32.3 & 5.2 & 15.7 & 37.4 & 18.8 & 19.5 & & - & 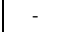 & - & - & 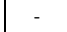 & - & - & - & 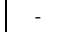 & - & & - \\
\hline
\end{tabular}

Tabela 5. Comparação entre os valores composicionais do gabro de Lídice (GL) e gabros mineralizados em Fe-Ti-V e de diferentes ambientes tectônicos. OIT = ocean island tholeiite e WPB = within-plate basalt (Karkkainen \& Bornhorst, 2003; Sarapää et al., 2005; Hou et al., 2012; Abu El-Ela, 1996; Pang, 2008).

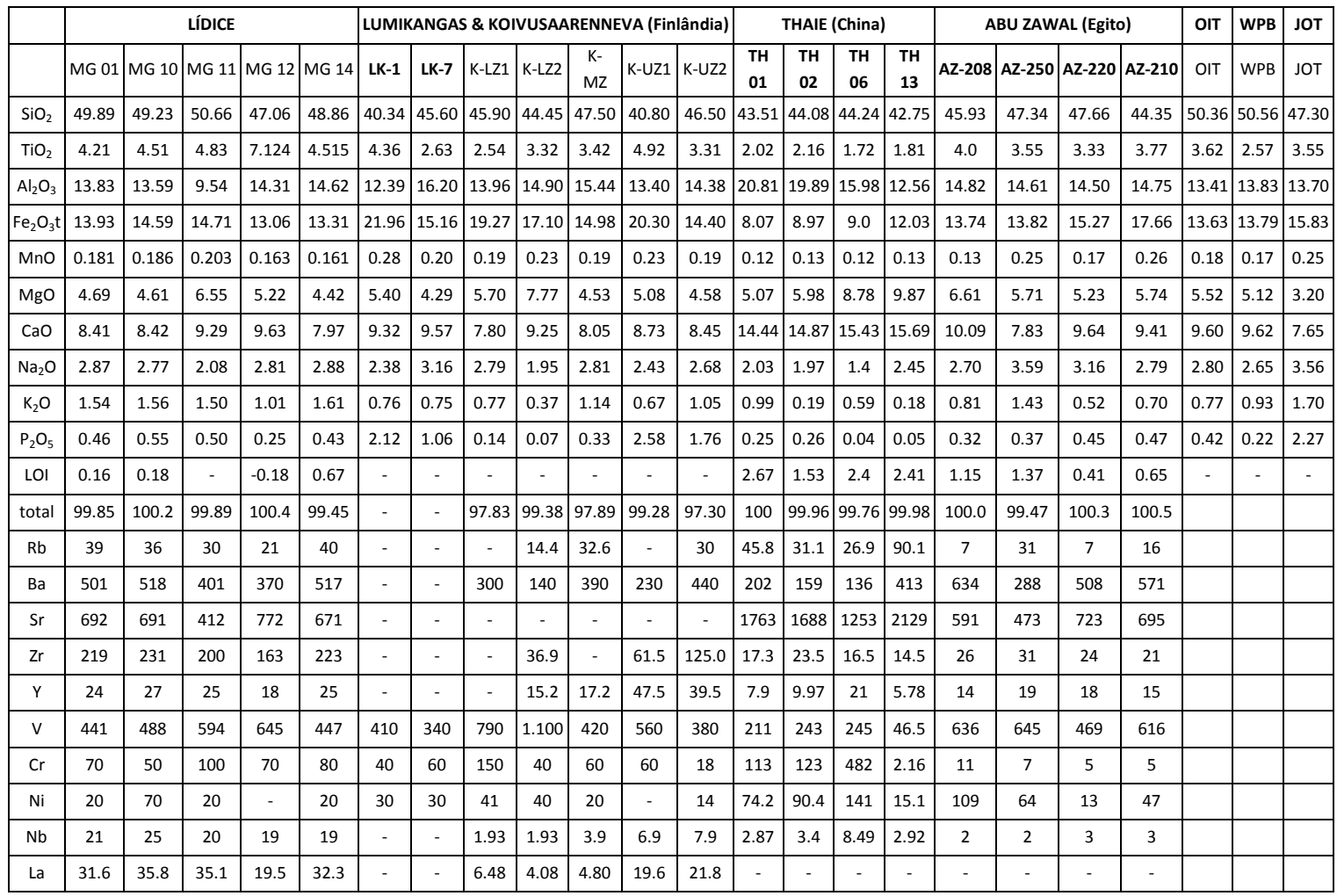




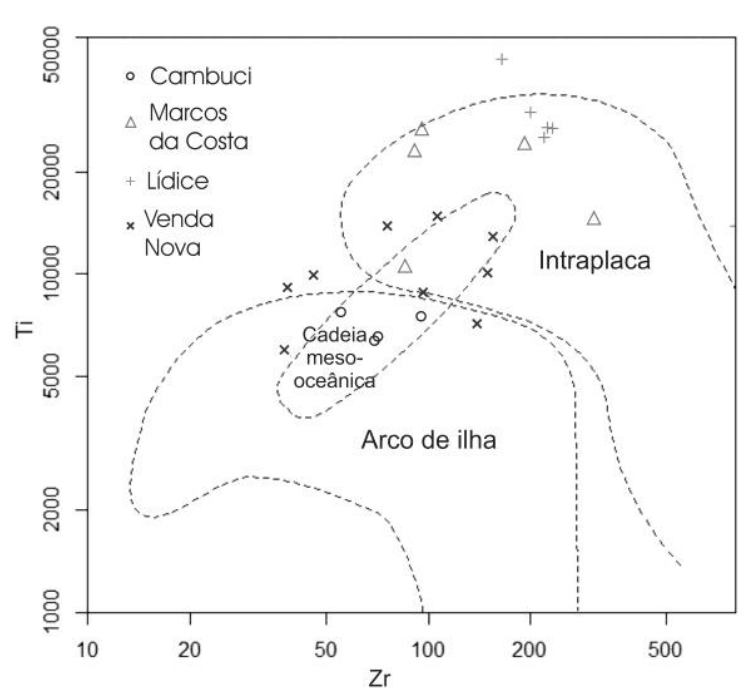

Figura 12. Diagrama discriminante Zr x Ti (Pearce, 1982) para os gabros posicionados no trend oriental (Lídice, Marcos da Costa, Cambuci e Venda Nova).

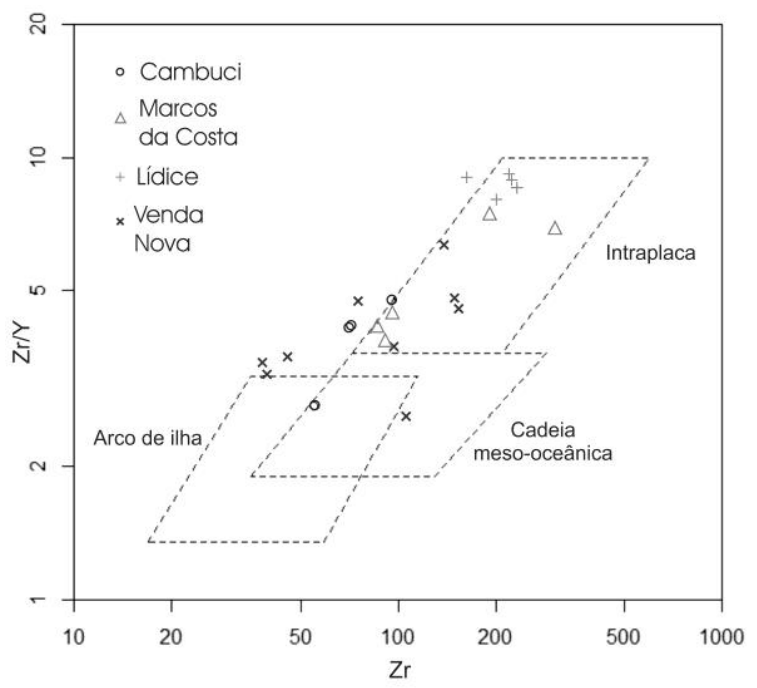

Figura 13. Diagrama discriminante $Z r-Z r / Y$ (Pearce \& Norry, 1979) para os gabros posicionados no trend oriental (Lídice, Marcos da Costa, Cambuci e Venda Nova).

Em diversos pontos do corpo gabroide foram constatadas variações bruscas nas medidas de SM em escala centimétrica, com valores que variaram de um máximo de $87.5 \times 10-4$ a um mínimo de 0.79 x10-4 SI-emu (Tabela 6). Essas variações nas medidas de SM no maciço gabroide foram interpretadas como resultante da presença de níveis / bandas centimétricas a decimétricas com concentrações anômalas de titanomagnetita, o que possivelmente represente um bandamento magmático.

A maior fugacidade em oxigênio, ou o seu incremento, durante o processo de cristalização magmática, favoreceria a presença da magnetita como o principal óxido de $\mathrm{Fe}-\mathrm{Ti}$ enquanto a baixa fugacidade permitiria o surgimento da ilmenita. Já um incremento de $\mathrm{fO} 2$, ainda dentro de um regime de baixa fugacidade, proporcionaria a cristalização do ulvospinélio - Ti-magnetita, além da ilmenita (Buddington \& Lindsley, 1964; Mathison, 1975). Dentro dessa perspectiva, a presença da titamomagnetita e da ilmenita associada ao gabro de Lídice indica que, provavelemente, foram essas as condições que ocorreram durante a cristalização desse corpo.

Tabela 6. Medidas da susceptibilidade magnética no maciço gabroide.

\begin{tabular}{ccccccccccccc}
\hline \multicolumn{8}{c}{ Susceptibilidade Magnética (x10-4 SI emu) } \\
\hline Ponto & SM-1 & SM-2 & SM-3 & SM-4 & SM-5 & SM-6 & SM-7 & SM-8 & SM-9 & SM-10 \\
\hline MG-01A & 30.4 & 38.3 & 26.9 & 45.2 & 46 & 14.5 & 44 & 38.7 & 26.7 & 19 \\
\hline MG-10 & 12.4 & 16.2 & 6.94 & 2.77 & 12.7 & 4.77 & 9.08 & 6.32 & 3.65 & 8.07 \\
\hline MG-11 & 0.79 & 5.63 & 5.23 & 6.18 & 5.55 & 5.13 & 3.59 & 5.81 & 5.7 & 7.14 \\
\hline MG-12 & 15.8 & 18.9 & 18.4 & 12.7 & 11.4 & 12.4 & 15.5 & 13.3 & 10.7 & 23.2 \\
\hline MG-14 & 48.2 & 12.6 & 11.7 & 82.5 & 9.33 & 9.75 & 12.2 & 87.5 & 83.2 & 6.66 \\
\hline
\end{tabular}

\section{CONCLUSÕES}

O Gabro de Lídice é constituído por hiperstênio, diopsídio, olivina, plagioclásio e óxidos de Fe e Ti que ocorrem sob a forma de grãos subedrais disseminados na rocha. 0 principal mineral ferromagnético corresponde à titanomagnetita vanadinífera, com inclusões e exsoluções de ilmenita, e com conteúdo de até 2,07\% de V2O5.

Os valores de titânio e vanádio do gabro de Lídice, compatíveis aos encontrados em minas de Fe-Ti-V associadas a gabros da Finlândia, China e Egito, em conjunto com o seu conteúdo em peso de titanomagnetita (entre $7,0 \%$ e $25 \%$ ) apontam, preliminarmente, para o potencial econômico desse corpo.

A coexistência de orto e clinopiroxênios com plagioclásio indica uma associação mineral original anidra. Suas assinaturas petrográfica e geoquímica são próprias de toleítos, posicionando-se no limite entre os campos alcalino e subalcalino, com uma origem gabroica associada a ambiente intraplaca.

Variações bruscas nas medidas de susceptibilidade magnética são interpretadas como resultante da presença de finas bandas com concentrações anômalas de titanomagnetita no maciço, possivelmente representando um bandamento magmático.

\section{AGRADECIMENTOS}

Nossos agradecimentos ao prof. Dr. Mauro Cesar Geraldes e aos revisores da GEONOMOS, pelas observações e críticas a esse trabalho, o que, sem dúvida, em muito contribuiu para a melhoria do mesmo. 


\section{REFERÊNCIAS}

Buddington A.F., Lindsley D.H. 1964. Iron-titanium oxide minerals and synthetic equivalents. J. Petrol., 54: 310 -357.

Chaves M. L. S. C., 1987. Geologia das mineralizações sulfetadas da região de Lídice (Rio Claro, RJ). Dissertação de Mestrado, Instituto de Geociências, Universidade Federal do Rio de Janeiro, Rio de Janeiro, 186 p.

Cox K. G., Bell, J.D., Pankhurst, R.J. 1979. The Interpretation of Igneous Rocks. George Allen \& Unwin, London, $450 \mathrm{p}$.

Dutra, A. C. D., 2013. Metalogenia em terrenos de alto grau: Contexto geológico e propostas para o modelo de geração das mineralizações sulfetadas de Rio Claro, RJ. Dissertação de Mestrado, Universidade do Estado do Rio de Janeiro. $124 \mathrm{f}$.

Heilbron, M., Mohriak, W., Valeriano, C.M., Milani, E., Almeida, J.C.H., Tupinambá, M., 2000. From collision to extension: the roots of the South-eastern continental margin of Brazil. In: Talwani, Mohriak (Eds.), Atlantic Rifts and Continental Margin. AGU Geophysical Monograph Series, v. 115, 354 pp.

Heilbron, M., Pedrosa-Soares, A. C., Campos Neto, M., Silva, L. C., Trouw, R., Janasi, V. 2004. A Província Mantiqueira: In: MANTESSO-NETO, V.; BARTORELLI, A.; CARNEIRO, C.D.R., BRITO NEVES, B.B.. Geologia do Continente Sul-Americano: Evolução da Obra de Fernando Flávio Marques de Almeida, 11, p.: 203-234.

Heilbron, M., Almeida, J. C. H, Silva, L. G. E., Palermo, N Tupinambá, M., Duarte, B. P., Valladares, C., Ramos, R., Sanson, M., Guedes, E., Gontijo, A., Nogueira, J.R., Valeriano, C., Ribeiro, A., Ragatky, D. 2007. Geologia da Folha Volta Redonda- SF.23-Z-A-V, escala 1:100.000: nota explicativa integrada com Santa Rita do Jacutinga, Barra do Piraí, Angra dos Reis - Rio de Janeiro/São Paulo: Ministério de Minas e Energia / Companhia de Pesquisa de Recursos Minerais / Universidade do Estado do Rio de Janeiro.

Hou T., Zhang. Z., Encarnacion, J., Santosh, M., 2012. Petrogenesis and metallogenesis of the Taihe gabbroic intrusion associated with Fe-Ti-oxide ores in the Panxi district, Emeishan Large Igneous Province,southwest China. Ore Geology Reviews 49: 109-127

Irvine, T. N. \& Baragar, W. R. A. 1971. A Guide to Chemical Classification of the Common Volcanic Rock. Canadian Journal of Earth Sciences, 8: 523-548.

Karkkainen, N.. K. \& Bornhorst, T. J. 2003. The Svecofennian gabbro-hosted Koivusaarenneva magmatic ilmenite deposit, Kalvia, Finland. Mineralium Deposita 38: 169-184.

Ludka, I. \& Wiedemann, C.M. 1997. O gabro coronítico de Amparo, RJ - Petrografia, Química Mineral e Geotermometria. Anuário do Instituto de Geociências, 20:143-162.

Mathison, C. I. 1975. Magnetites and ilmenites in the Somerset Dam layered basic intrusion, southeastern Queensland Lithos, 8: 93-111.
Mcdonough, W. F. \& Sun, S. S. 1995.The composition of the Earth. Chemical Geology, 120: 223-253.

Mendes, J.C., Fonseca, M.J.G., Moura, J.C. 2011. Petrografia e Geoquímica de rochas metaultramáficas da região de Cambuci, Rio de Janeiro. Anuário do Instituo de Geociências UFRJ, 34(1): 22-32.

Mendes J. C., Wiedemann C M., McReath I., 2002. Norito e Charnoenderbitos da Borda do Maciço Intrusivo de Venda Nova, Espírito Santo. Anuário do Instituto de Geociências UFRJ Volume 25

Pang, K. N., 2008. Origin of the Permian Panzhihua Layered Gabbroic Intrusion and the hosted Fe-Ti-V oxide deposit, Sichuan Province, SW China. (Unpublished thesis). University of Hong Kong, 285p

Pearce, J. A. 1982. Trace element characteristics of lavas from destructive plate boundaris. In: R. S. Thorpe (Eds.): Orogenic Andesites and Related Rocks. Chichester: Wiley \& Sons, p.: 437-464.

Pearce, J. A. \& Norry, M. J. 1979. Petrogenetic Implications of Ti, $\mathrm{Zr}, \mathrm{Y}$ and $\mathrm{N}$ b Variations in Volcanic Rocks. - Contrib. Miner. Petrol., 69: 33-47.

Pereira, R. M., Neumann, R., Salomão, M. 2015. Mineralização de Fe-Ti-V em gabro granulitizado da região de Rio Claro, RJ. In: Anais, GEOSUDESTE 2015. 14 Simpósio de Geologia do Sudeste, Campos do Jordão, SP.

Sarapää O., Kärkkäinen, N., Chernet, T., Lohva, J., Ahtola, T., 2005. Exploration results and mineralogical studies on the Lumikangas apatite-ilmenite gabbro, Kauhajoki, western Finland. Geological Survey of Finland, Special Paper 38, 3141.

Souza, G.A. 2010. Estudo de metagabro em unidade précambriana na Ladeira do Grego, Paracambi, RJ. Monografia (Graduação em Geologia) - Universidade Federal Rural do Rio de Janeiro - UFRRJ, Departamento de Geociências, 2010. 53 p.

Sun, S. S. \& Mcdonough, W.F. 1989. Chemical and isotopic systematics of oceanic basalts: implications for mantle composition and process. In: Saunders, A.D.\& Norry, M.J. (Eds.), Magmatism in the Ocean Basins. Geological Society Special Publication, 42: 313-345

Trotta, M.C. 2004. Análise estrutural dos diques e brechas tectônicas da região leste do gráben da Guanabara, Estado do Rio de Janeiro. Monografia de Graduação, Instituto de Geociências, Instituto de Geociências, Universidade Federal do Rio de Janeiro, $60 \mathrm{p}$

Wild, S.A., Dorsett-Bain, H.L., Lennon, R.G. 1999. Geological setting and controls on the development of graphite, sillimanite and phosphate mineralization within the Jiamusi Massif: An exotic fragment of Gondwanaland located in north-eastern China? Gondwana Research, 2 (1): 21-46.

Winchester, J.A. \& Floyd, P. A. 1977. Geochemical discrimination of different magma series and their differentiation products using immobile elements. Chemical Geology, 20, 325-343. 